\title{
Laboratory study of salinity and surfactant concentration effects on oil recovery
}

\author{
Widia Yanti $^{1, *}$, Sugiatmo Kasmungin ${ }^{1}$, Rabiatul Adawiyah ${ }^{2}$, and Blandina Kolanus ${ }^{2}$ \\ ${ }^{1}$ Department of Petroleum Engineering Faculty of Earth Technology and Energy Trisakti University, 11440 Jakarta, Indonesia \\ ${ }^{2}$ Student of Department of Petroleum Engineering Faculty of Earth Technology and Energy Trisakti University, 11440 Jakarta, Indonesia
}

\begin{abstract}
This paper perfoms a discussion of the result from two laboratory tests of surfactant injection. The first test is focused on the influence of salinity that varies between 5000 ppm- 9000 ppm with a concentration of $1 \%$ surfactant to the value of density, viscosity, interfacial tension, and Recovery Factor. The second test is performing the influence of surfactant concentration that varies between $0.1 \%-1 \%$ with a value of $5000 \mathrm{ppm}$ salinity to the value of residual oil saturation, density, viscosity, and interfacial tension. The result of the first test shows that along with the increase of salinity levels, the increase in viscosity and density will occured as well. However, variations in salinity does not affect to the value of interfacial tension. Meanwhile, on Recovery Factor testing, the Recovery Factor optimal value of $61.53 \%$ was obtained when the salinity levels $6,000 \mathrm{ppm}$. The result of the second test showed that the addition of surfactant concentration lead to a decrease in the residual oil saturation and interfacial tension, but it may cause an increase in density and viscosity.
\end{abstract}

\section{Introduction}

Based on BP Statistical Review 2013, Indonesia oil production has been declined since 1995 [1]. However, oil consumption still increase year by year due to the economic growth. This creates an unbalance condition between oil demand and supply [2]. Therefore, in order to create a stable condition, the Indonesian government together with the oil companies must work together to increase oil production from existing oil fields in Indonesia.

Chemical flooding, one of EOR methods, are now getting importance in enhanced oil recovery to recover the trapped oil after primary and secondary recovery. One of chemical flooding methods in the present study has been carried out on surfactant flooding. The chemicals with different compositions and combinations were used to recover the oil after conventional water flooding [3]. By applying primary and secondary oil recovery such as artificial lift and waterflooding, the average oil recovery still in between 5-30\% [4]. However, after primary and secondary recovery, original oil in place is still large (about 50 billion barrel) [5]. It creates a prospect for applying Enhanced Oil Recovery (EOR) application (under this method, oil recovery between $5-65 \%$ from original oil in place) [4].

Enhanced oil recovery (EOR) or tertiary recovery is considered for the solution of relatively low recovery efficiencies relating to petroleum production processes [6]. From the United States Departement of Energy, it is estimated that the full use of enhanced oil recovery in
United States could generate a additional 240 billion barrels of oil [7].

According to the US Department of Energy, there are three primary techniques for EOR : thermal recovery, gas injection, and chemical injection. The reservoir in this research will be injected by surfactant which is one of the chemical injection technique. The reason to select this technique is because of surfactant addition has become very attractive because of its ability to reduce surface/interfacial tension (IFT) between immiscible fluids. The interfacial tension plays a significant role in the process of enhanced oil recovery. The IFT reduces as the surfactant concentration increase [7].

Surfactants are chemical substances that adsorb on or concentrate at a surface or fluid-fluid interface and alter the interfacial properties significantly; in particular, they decrease interfacial tension (IFT) [8]. Based on the nature of the hydrophilic part the surfactant can be classified as anionic; cationic; amphoteric or Zwitterionic; and nonionic. In this research will be used AOS surfactants [7].

AOS (Alpha Olefin Sulfonate) surfactants are one of the anionic surfactants which are most widely used in EOR processes because they show relatively low adsorption on sandstone rocks whose surface charge is negative [3]. Moreover, AOS surfactants provide outstanding detergency, high compatibility with hard water, and good wetting and foaming properties with $\mathrm{CO}_{2}$ even when the porous medium is partially saturated with oil. These properties make AOS surfactants an excellent candidate for EOR project that aim to produce more oil from underground reservoirs [9]. Beside of that,

*orresponding author: widiayanti@gmail.com 
AOS surfactants have good stability at high temperature [10].

Due to the high cost of the chemicals, the economics of the surfactant injection is very important. Thus optimum injection scheme has to be designed and considered [11].

This research is preliminary study to investigate the effects of surfactant concentration on enhanced oil recovery. The objective of this research is to determine the optimum of surfactant concentration to obtain high oil recovery.

\section{Experimental details}

This research was divided into two group of tests. First group discusses the influence of salinity that varies between 5000 ppm - 9000 ppm with a concentration of $1 \%$ surfactant to the value of density, viscosity, interfacial tension, and Recovery Factor (RF). The second test discusses the influence of surfactant concentration that varies between $0.1 \%-1 \%$ with a value of $5000 \mathrm{ppm}$ salinity to the value of residual oil saturation, density, viscosity, and interfacial tension. For more details, following an experimental procedure in this study, namely: (A) Preparation of the brine solution; (B) Preparation of the surfactant solution, (C) Measurement of physical properties of the solution, and (D) the process of surfactant injection into the reservoir model (sandpack).

\subsection{Preparation of the Brine Solution}

Brine was used as the aqueous phase during research. The basic ingredient of the brine solution that used in this research is $\mathrm{NaCl}$ with $5000 \mathrm{ppm}$ concentration. There are some steps to see the influence of salinity on physical properties of the solution and Recovery Factor (RF).

First of all, by using magnetic stirrer, the $5000 \mathrm{ppm}$ of $\mathrm{NaCl}$ mixed with $1000 \mathrm{ml}$ of pure water until the $\mathrm{NaCl}$ dissolved completely. Then the brine solution conducted with varying salinity levels, ie $5000 \mathrm{ppm}$, 6000 ppm, 7000 ppm, 8000 ppm, and 9000 ppm.

\subsection{Preparation of the Surfactant Solution}

To prepare the surfactant solutions, the $5000 \mathrm{ppm}$ of brine mixed with $10 \mathrm{ml}$ of AOS surfactants using magnetic stirrer. Mixed them, until the AOS surfactant are dissolved completely. Repeat this steps for each salinity level (6000 ppm - $9000 \mathrm{ppm})$. In this research, AOS surfactants concentration varies : $0.1 \% ; 0.5 \% ; 1 \%$; and $1.5 \%$. It mean the AOS surfactants needed are respectively $1 \mathrm{ml} ; 5 \mathrm{ml} ; 10 \mathrm{ml}$; and $15 \mathrm{ml}$.

\subsection{Measurement the Physical Properties of the Solution}

The physical properties of the solution to be counted are viscosity (brine and brine+AOS surfactants), density (brine and brine+AOS surfactants), and surface tension (brine and brine+AOS surfactants). The viscosity is measured using viscometer Oswald. Then the density is measured using picnometer. And the surface tension is measured using tensionmeter Du Nouy.

\subsection{The Process of Surfactant Injection into the Reservoir Model}

The objective of this step is for knowing the Recovery Factor (RF) value of each solution and could determine which one has the optimum salinity concentration. First step, prepare the reservoir model using a sandpack as a media. The volume and size of the sand is respectively $54.19 \mathrm{ml}^{3}$ and $80 \mathrm{mesh}$. Second step, preparing a brine saturation inside the reservoir model. In this step, the pressure used is 2 psi. Third step, preparing a parafin saturation inside the reservoir model. In this step, the pressure used is 1 psi - 2 psi. Fourth step, preparing a water injection. Fifth step, preparing the AOS surfactants to be injected into reservoir model. The total of the RF value could be obtained from this step. Last step, preparing the brine to be injected into reservoir model as a preflush. Repeat this steps for each salinity level (5000 ppm - $9000 \mathrm{ppm})$ and for each AOS surfactant concentration $(0.1 \%-1.5 \%)$.

\section{Result and discussion}

\subsection{Density Measurement Results}

Density measurements conducted in the laboratory, using picnometer. Here, on Figure 1 below, are the result of the fifth density measurements on a brine solution that varies between $5000 \mathrm{ppm}-9000 \mathrm{ppm}$.

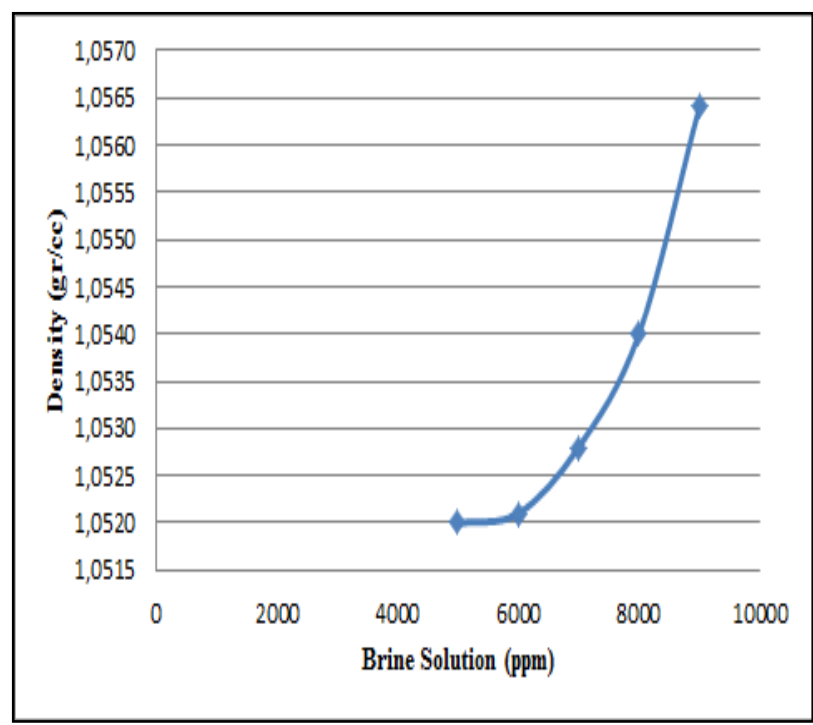

Fig. 1. The brine solution vs density

From Figure 1 above shows that the increased salinity levels will increase the value of its density. In this study, the density test conducted using a brine solution that varies between $5000 \mathrm{ppm}-9000 \mathrm{ppm}$. 
In the second test, the AOS surfactants are added into the solution. Here are the results of measurements of the density after the adding of AOS surfactants.

Figure 2 below shows that the increased brine solution with $1 \%$ AOS surfactants, will increase the value of its density. In this study, the density test conducted using the brine solution with the adding of the $1 \%$ AOS surfactants concentration that varies between 5000 ppm - 9000 ppm.

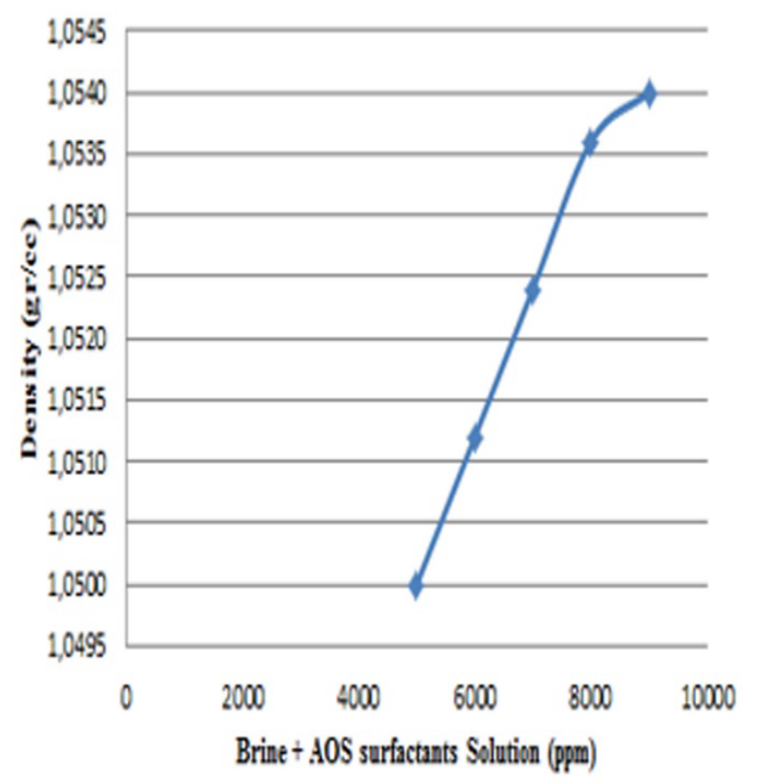

Fig. 2. The brine solution after AOS surfactant added into the solution vs density .

\subsection{Viscosity Measurement Results}

The viscosity measurements conducted in the laboratory using Oswald viscometer. On the measurement of the viscosity of the surfactant solution used only one concentration of the same for the fifth solution, ie $1 \%$.

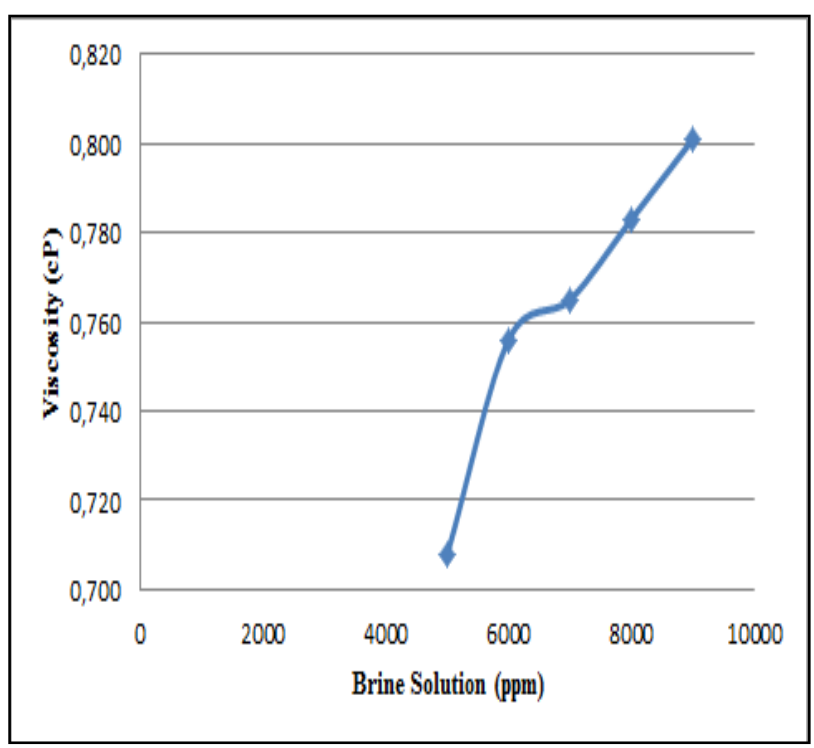

Fig. 3. The brine solution vs viscosity
In this study, it presents the results of measurements of the viscosity of the surfactant solution which varies between 5000 ppm - 9000 ppm. Figure 3 shows that the increase in salinity levels will increase the viscosity value. The results of measurements of the viscosity of the surfactant solution which varies between $0.1 \%-1 \%$ were then discussed here.

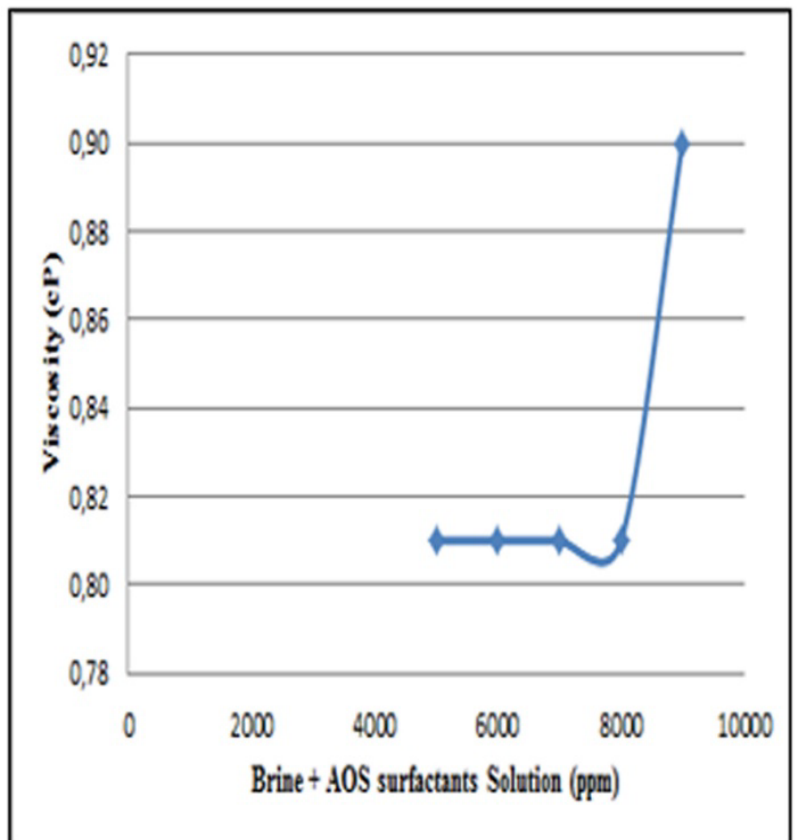

Fig. 4. The brine solution after AOS surfactant added into the solution vs viscosity

Figure 4 shows that the increase in the concentration of surfactant will increase the viscosity value. It followed by a discussion on the results of measurements of the viscosity after the adding of AOS surfactants.

\subsection{Surface Tension Measurement Results}

Surface tension measurements performed in the laboratory using a Du Nouy tensiometer. surface tension measurements performed twice, ie measurement of surface tension surfactant solution and measurement variation surfactant solution.

At surface tension measurement of the surfactant solution used only one concentration of the same for the fifth solution, ie $1 \%$. The following surface tension measurement results to the surfactant solution which varies between $5000 \mathrm{ppm}-9000 \mathrm{ppm}$.

From figure 5, it shows that increasing salinity levels will impact the value of surface tension. Surface tension value increases with the concentration of salinity. Here are the results of surface tension measurement of the surfactant solution which varies between $0.1 \%-1 \%$.

From figure 6, it shows that the increase in the concentration of surfactant will affect the value of surface tension. Surface tension value decreased with increasing concentration of surfactant. 


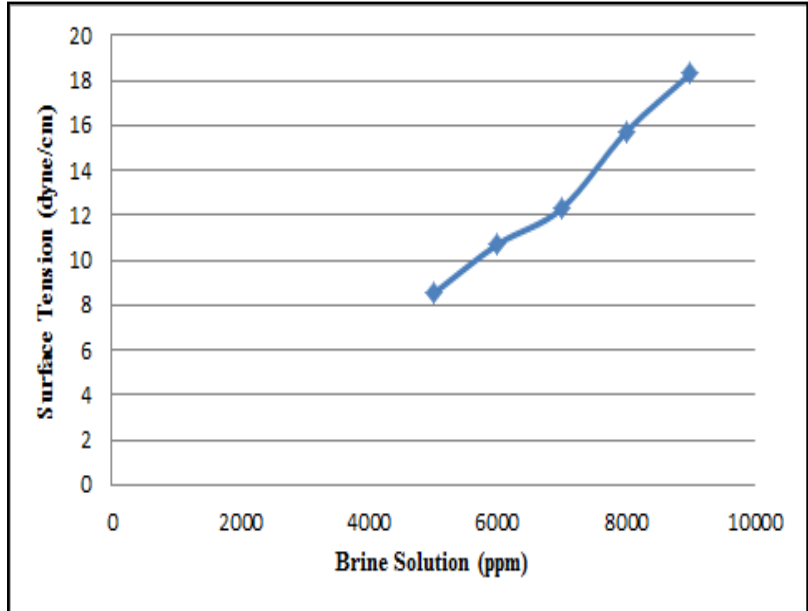

Fig. 5. The brine solution vs surface tension

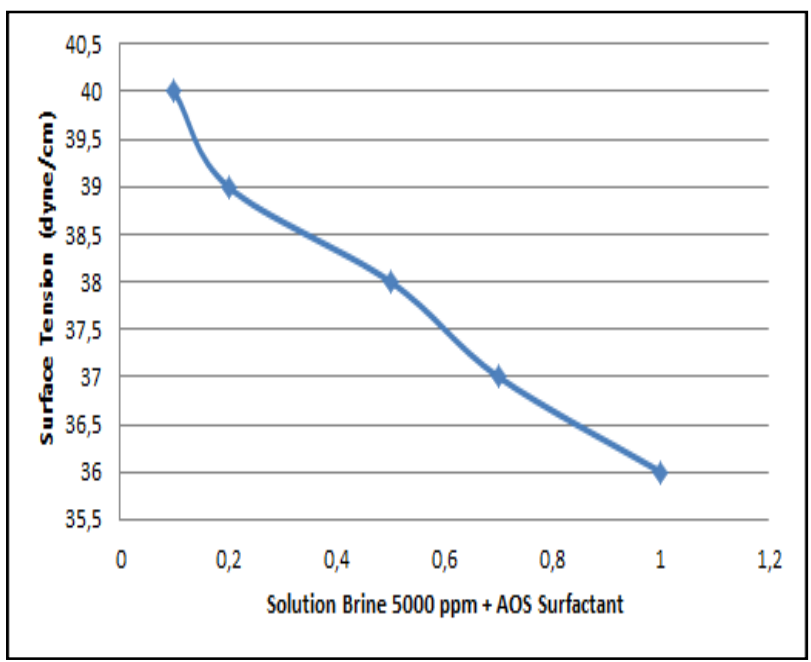

Fig. 6. The brine solution after AOS surfactant added into the solution vs surface tension

\subsection{The Results of Surfactant Injection Into Reservoir Model to Determine the Optimum Salinity}

The purpose of this test is to determine the optimum salitnity. Here are the results of surface injection into reservoir model.

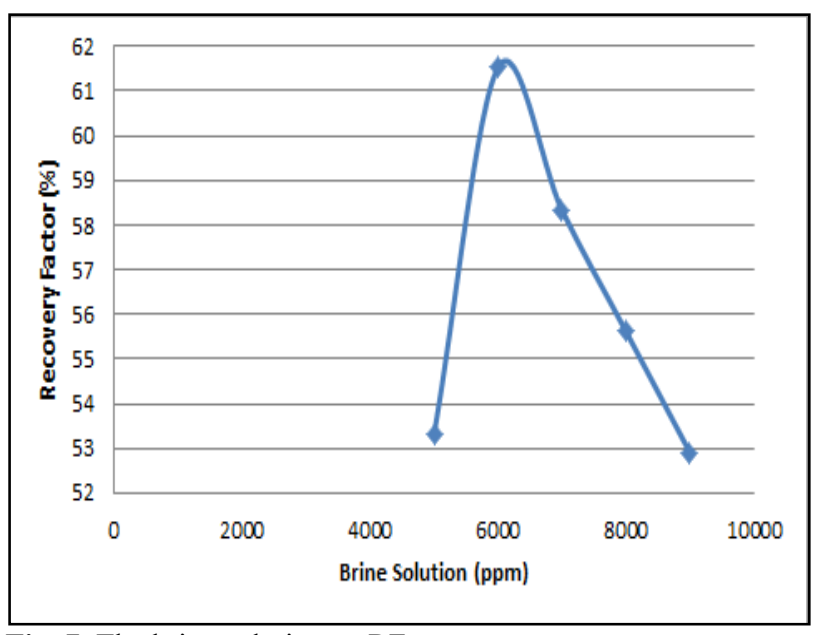

Fig. 7. The brine solution vs RF
From Figure 7, it shows that the solution to the salinity of $6,000 \mathrm{ppm}$ yield the most optimum RF. In this study, each solution is conducted an injection using $1 \%$ surfactant concentration and the brine solution are varies between $5000 \mathrm{ppm}-9000 \mathrm{ppm}$.

\subsection{The Results of Surfactant Injection Into Reservoir Model to Determine the Maximum Surfactant Concentration}

The purpose of this test is to determine the optimum salitnity. Here are the results of surface injection into reservoir model.

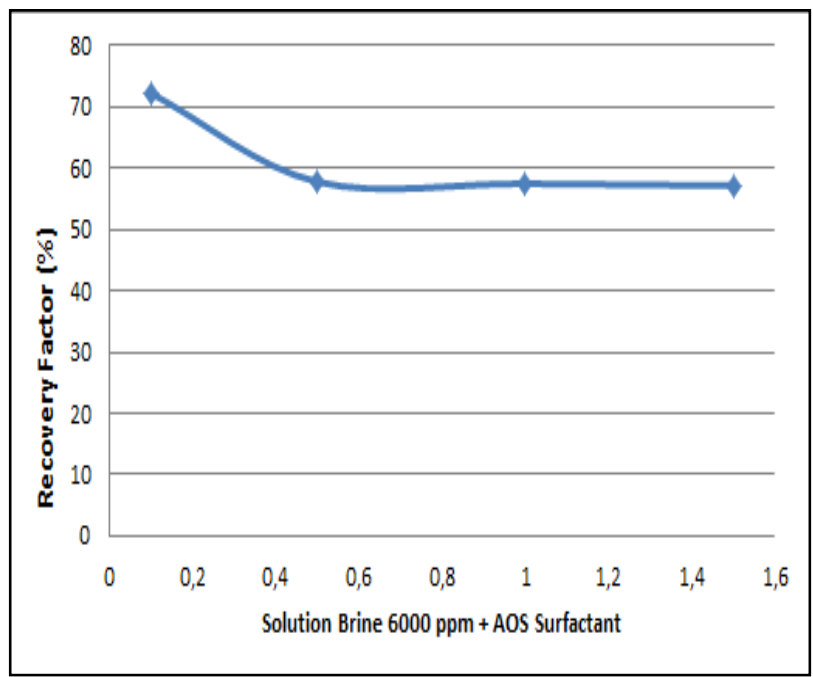

Fig. 8. The various AOS concentration vs RF

Figure 8 shows the solution to the salinity of 6,000 ppm provides the most optimal RF, then the reinjection process to determine the most optimal concentration using a salinity of $6,000 \mathrm{ppm}$. The result of the test is the surfactant concentration of $0.1 \%$ yield the most maximum RF.

\section{Conclusion and recommendation}

\section{a. Conclusion}

Based on the analysis and calculations have been conducted in this research, there are several conclusions.

(1) Increased levels of salinity and concentrations of surfactants will increase the value of density;

(2) Increased levels of salinity and concentrations of surfactants will increase the value of viscosity;

(3) Increased levels of salinity and concentrations of surfactants will increase the value of IFT;

(4) The solution which has the most optimum salinity is a solution with $6000 \mathrm{ppm}$ salinity. This solution has the greatest RF, about $61.53 \%$;

(5) The solution which has the most optimum surfactant concentration is a solution with $0.1 \%$ surfactant concentration. This solution has the greatest RF, about $72.22 \%$; 
(6) Applying a 6000 ppm salinity and $0.1 \%$ surfactant concentration into a solution, will caused a significant increasing of RF (is around $30 \%)$.

\section{b. Recommendation}

Recommendation for the next research is to find a critical surfactant concentration which is very important from the economic point of tertiary recovery (chemical flooding) since the use of surfactants is expensive.

Critical micelle concentration (CMC) refers to the concentration of surfactant solutions to form a large amount of micelles as one of the main parameters of each surfactant [9]. Critical micelle concentration can be determined from plot of interfacial tension (IFT) and surfactant concentration [3]. CMC values are important in all surfactant applications realted to the petroleum industry.

\section{References}

1. http://crudeoilpeak.info/peak-oil-and-fuel-subsidiesin-indonesia (accessed:August 18, 2016).
2. M. Abdurrahman, W.S. Bae, A. Novriansyah, and I. Khalid. The IRES International Conference, 9-12 (2016).

3. Samanta, A., Bera, A., Ojha, K. et al. J Petrol Explor Prod Technol (2012)

4. L.W. Lake, Enhanced Oil Recovery (1989).

5. SKK Migas Annual Report (2012).

6. F.D.S. Curbelo, A.I.C. Garnica, T.N.C. Dantas, E.L. B. Netto, Oil Rec. by Ion. Surf. and Swe. Eff. Stu. in Sands. Brazilian Journal of Petroleum and Gas, V.2, 9-16 (2008).

7. J.A. Xavier, Effect of Varying Surfactant Concentration on Interfacial Tension in Tertiary Recovery of Crude Oil (2011).

8. D.W. Green, and G.P. Willhite, E.O.R. Society of Petroleum Engineers Inc. (1998).

9. R. Farajzadeh, R. Krastev, and P.L.J. Zitha, Foa. Fil. Stab. w. A.O.S. Journal of ELSEVIER 35-40 (2008).

10. http://jpchemicals.in/a-o-s/ (accessed:November 01, 2016).

11. T. Babadagli, A. Al Bemani, F. Boukadi, R. Al Maamari, A Lab. Feas. Stu. of Dil. Surf. Inj. Journal of Petroleum Science and Engineering, 48, 37-52 (2005). 